The International Journal of Flexible Manufacturing Systems, 7 (1995): 103-125

(C) 1995 Kluwer Academic Publishers, Boston. Manufactured in The Netherlands.

\title{
Monitoring and Classification of Dimensional Faults for Automotive Body Assembly
}

\author{
CHINMO ROAN \\ Department of Mechanical Engineering and Applied Mechanics, The University of Michigan, Ann Arbor, MI 48109 \\ S. JACK HU \\ Department of Mechanical Engineering and Applied Mechanics, The University of Michigan, Ann Arbor, MI 48109
}

\begin{abstract}
Sudden process changes occurring during automobile body assembly processes will influence the downstream assembly process and the functionality and final appearance of the vehicle. Furthermore, these faults could result in a decreased production rate and an increase in the cost if sudden process changes are so serious that the production line has to be stopped for investigation. Thus, sudden process changes should be detected and eliminated as soon as possible to prevent defective products from being produced and to reduce the cost of repairs/ reworks. A monitoring algorithm is developed to detect, classify, and group process changes by analyzing the dimensional data of car bodies. The results of this monitoring algorithm can help diagnose the root causes of variation according to the locations of measurement points, body structure, assembly sequence, and tooling layout. Measurement data obtained from an optical coordinate measuring machine (OCMM) are used to demonstrate the monitoring technique.
\end{abstract}

Key Words: sudden process change, OCMM, BIW, detection algorithm, monitoring algorithm, mean shift, sporadic jump, variance change.

\section{Introduction}

An automobile body-in-white (BIW) is the frame of an automobile body before panels are fitted. Dimensional variation of the BIW will influence quality and functionality of the vehicle, for example, wind noise, water leakage, door closing effort, gap, and flush variation, etc. Therefore, dimensional variations on the BIWs must be detected and eliminated to prevent defective cars from being produced and to improve the dimensional quality of automobile bodies.

One cause of the dimensional variation is sudden process changes during the assembly process. The most frequently occurring sudden process changes are sustained mean shifts, sporadic jumps, variance changes, and/or any combination of these three. Figure 1 shows an example of a mean shift at point B-U/D at the motor rail. The horizontal and vertical axes represent the car number and measured deviation from design nominal (in $\mathrm{mm}$ ). A case of sporadic jumps is shown in figure 2 . Figure 3 shows a variance change and a mean shift occurring simultaneously at point $\mathrm{D}$.

The availability of $100 \%$ measurement data from an in-line optical coordinate measuring machine (OCMM) allows on-line detection of sudden process changes on the dimensions of a BIW. The OCMM was introduced to the automobile industry in the 1980s. An OCMM can measure every car assembled, resulting in 100\% measurement data (Wu and $\mathrm{Hu} 1990$ ). 

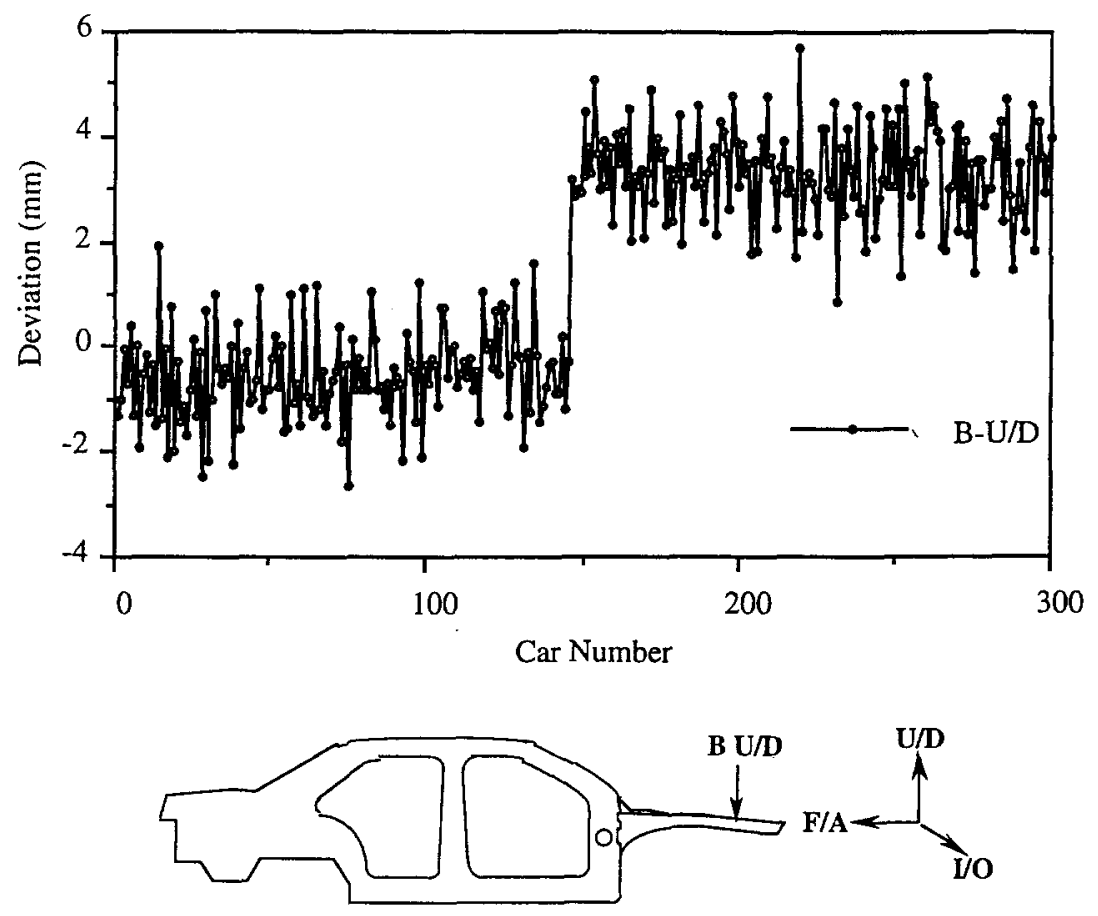

Figure 1. A mean shift occurred at measurement point B-U/D.

An OCMM can also measure a large number of points, say, 70 to 100 , on every car. Because of its high speed and reliability, the OCMM has become popular in many automobile assembly plants.

However, because of the lack of automatic monitoring and alarm systems in an OCMM, process faults such as those shown in figure 1 were usually undetected until the bodies reached later stages of the assembly process. In such cases, hundreds of cars with dimensional faults could be produced, significantly influencing the downstream assembly process and even requiring expensive repairs and reworks. Also, it is tedious and time consuming to manually handle the huge amounts of data generated by the OCMM.

Many authors have argued the concepts and methodologies of process control to improve the quality of the products before, during, and after manufacturing. Statistical process control (SPC) based on sampling inspection after products are manufactured was introduced by Shewhart (1931). The basic idea is to plot the sample mean and sample range $(\bar{X}$ and $R$ chart) to determine if the process is in control. If the process is out of control, one tries to locate the root cause and makes corrections. Taguchi (1986) used statistically designed experiments to design the product/process to be insensitive to environmental noise and component variation before manufacturing. Recently, simultaneous engineering tools have been used to reduce product development time and cost and to achieve higher quality by concurrently integrating a wide spectrum of product life cycle concerns.

Wu et al. (1989) suggested that real-time defect prevention in manufacturing can be achieved by fully utilizing $100 \%$ measurement data. Keats (1989) and Contreras (1989) 


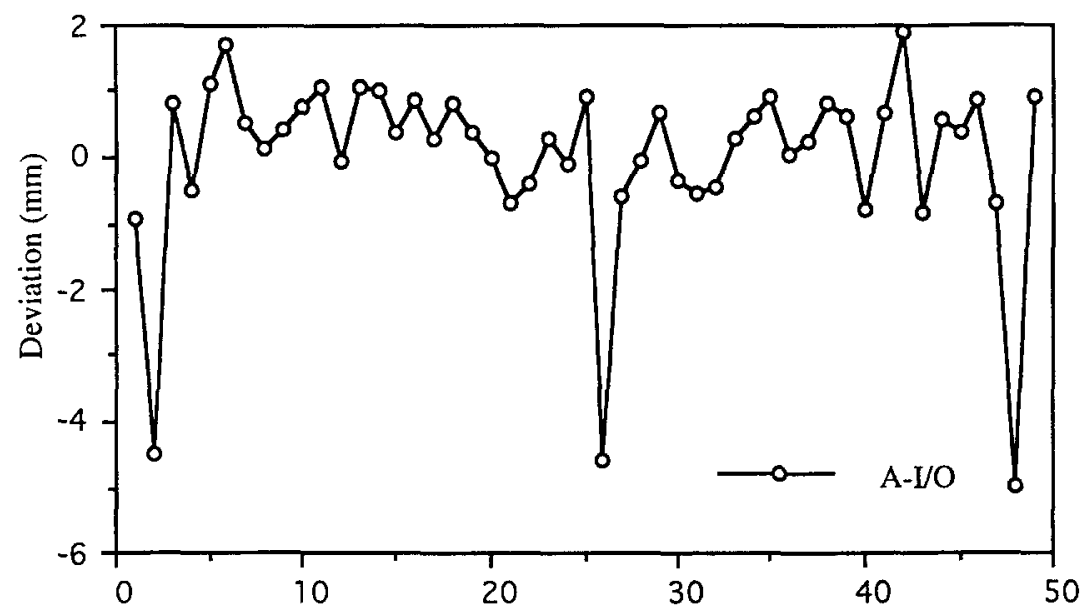

Car Number

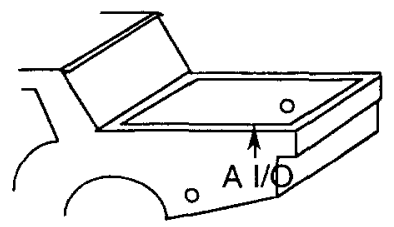

Figure 2. An example of sporadic jumps that occurred at the deck lid opening.

emphasize the important roles of SPC and on-line SPC in computer-integrated manufacturing. In addition, the integration of SPC and automatic process control is recognized as a technique for total system improvement (Box and Kramer 1992). Also, the fact that large volumes of data are involved suggests that computer processing action would make the information more effective (Hawkins 1974).

There exists a large body of literature emphasizing improving the strategies to increase the efficiency of conventional control charts, such as $\bar{X}$ and $R$ charts and Cusum chart, but, still, they can only determine if the process is in control. Dooley and Kapoor (1990a, 1990b) went one step further. They introduced an enhanced quality evaluation system which can detect and classify changes of continuous manufacturing processes using time series models, Cusum charts, chi-squared tests, autocorrelation charts, and a rule-based classifier. In addition, it was stated that "Experience shows that many SPC attempts fail to produce meaningful results because of the lack of diagnostic support for the effort"' (Guo and Dooley 1992).

In this paper, a monitoring algorithm is proposed to detect sudden process changes and help diagnose the root causes using the knowledge of the hierarchical structure of the BIW. This monitoring algorithm, implemented in the form of a computer program, is developed to detect and classify sudden process changes, and group the measurement points with sudden process changes within a few BIWs after changes occur by recursively monitoring 

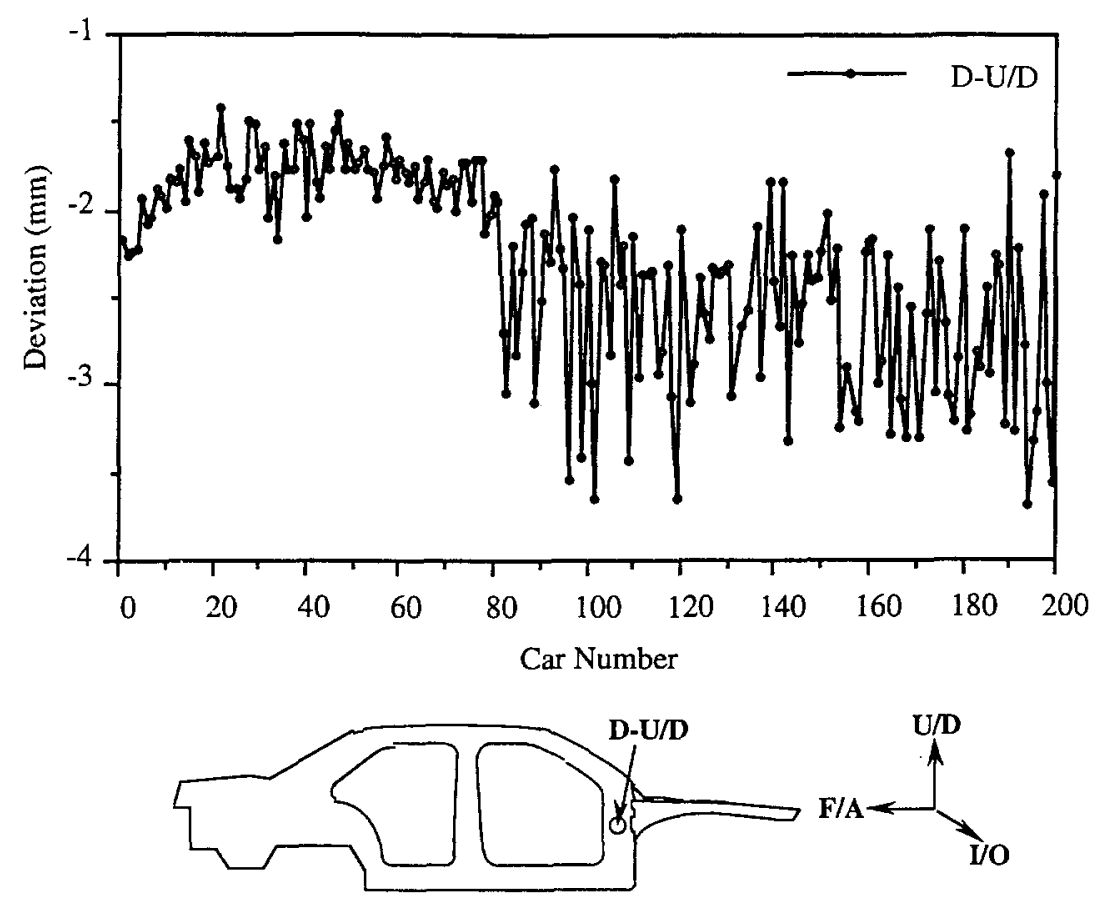

Figure 3. A variance change and a mean shift occurred simultaneously at point D-U/D.

OCMM data on-line. This algorithm, based on statistical techniques and the knowledge of body structure and body assembly process, can

1. Detect which BIW and which measurement point have sudden process changes

2. Classify the process changes as mean shift, sporadic jump, variance change, or any combination of these three

3. Group the points, classified as having the same process change, based on the characteristic location for root cause diagnosis.

After a BIW is measured by the OCMM, three statistical indices (data index, sample mean index, and sample variance index) of each measurement point on the current BIW are estimated. These three indices of each measurement point on the current BIW will lead to certain assumptions, e.g., a point had a mean shift or a point had a sporadic jump. These assumptions are checked by decision-making rules and more statistics. After a process change is confirmed and classified, the points with the same process change will be grouped together according to their characteristic location for root cause diagnosis. According to the assembly process knowledge, a specific fault in a certain station can only cause a specific type of process change at certain measurement points. Then, root causes can be systematically located once the measurement points with the same process change are grouped based on the characteristics of the direction, opening, subassembly, or part. After the dimensional fault is detected, classified, and grouped in the shortest time by this algorithm, root 
causes can be investigated and located, and improvement action made to minimize the production of defective products.

This paper is organized as follows. The automobile body assembly process and the characteristic matrices of the measurement points on the BIW are described in section 2 . Section 3 introduces the algorithm for monitoring. In section 4 examples are used to demonstrate the monitoring technique.

\section{Automobile body assembly process and characteristic matrices}

In this section, the body structure, assembly process, and dimensional measurement systems are introduced. Characteristics matrices are established to relate the product and process knowledge with measurement location.

\subsection{Automobile body assembly process}

Figure 4 is the flowchart of the automobile body assembly process. Subassemblies (underbody, left and right lay-down side frames, roof, shelf, and rear end panel) are manufactured in different subassembly lines. These subassemblies are welded together to form a BIW at the body framing station. The relative positions among subassemblies before they are welded is shown in figure 5. After each BIW is produced, re-spot welding is applied to increase its dimensional integrity. The measurement system is located after the re-spot welding stage. Either coordinate measuring machine (CMMs) or OCMMs are used to measure the critical points on BIWs to check their dimensional quality. After being measured, the BIW is transferred to the panel hanging process.

Measurement locations on a BIW are determined jointly by product engineers and manufacturing engineers early before the product launch. In general, the measurements are located so that both the product characteristics and process characteristics are monitored simultaneously. The product characteristics of a BIW are the size and shapes of its openings

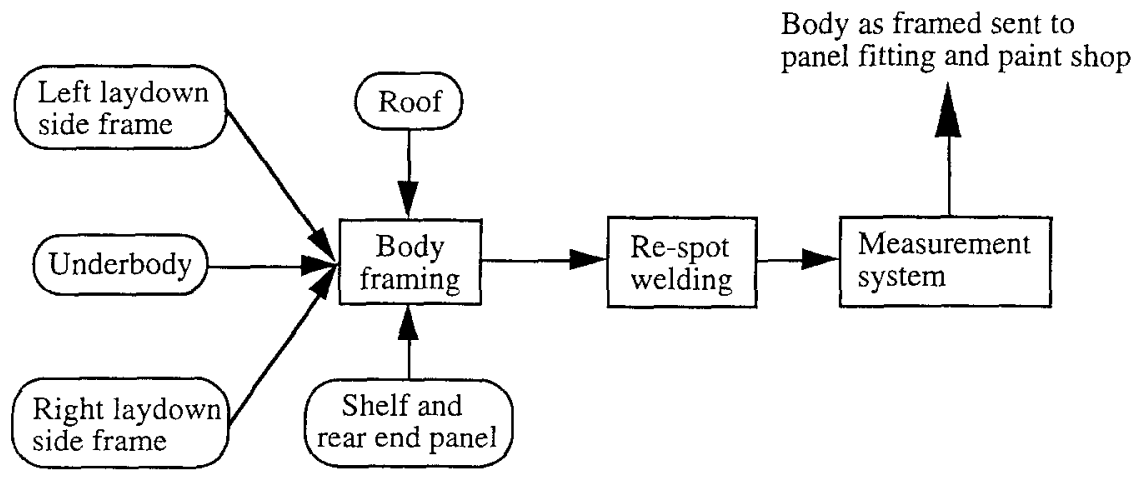

Figure 4. Flowchart of the body-in-white manufacturing process. 


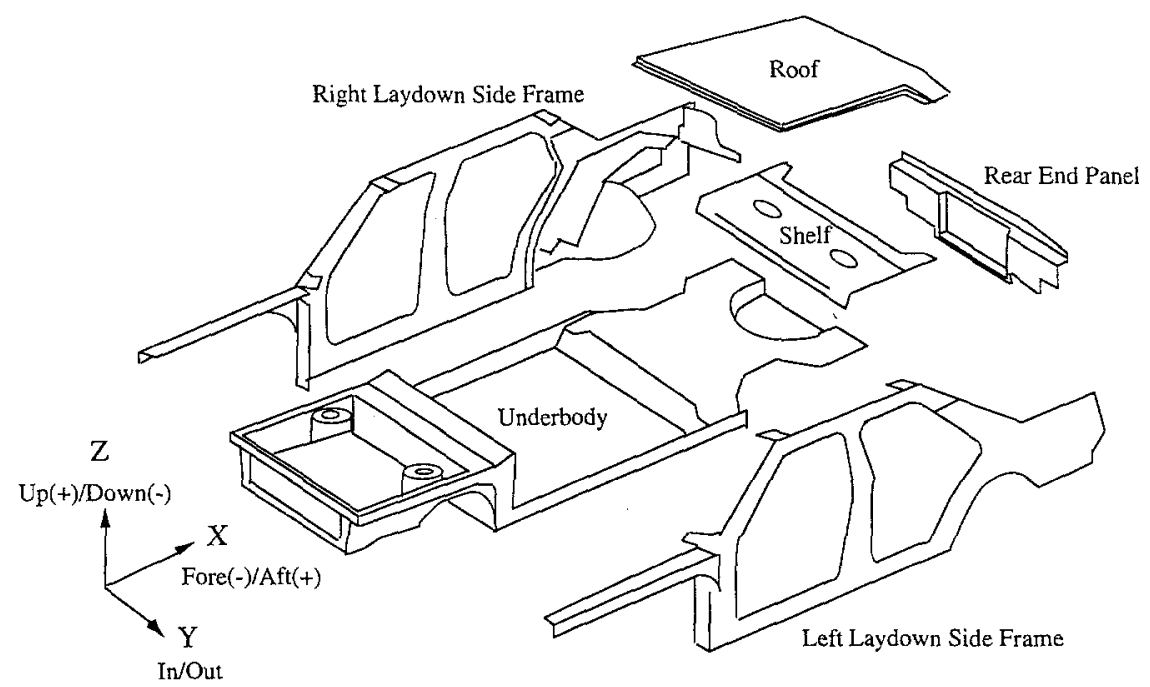

Figure 5. Structure of a BIW and its coordinate convention.

(e.g., door openings), because panels and trim parts will be fitted to these openings in the final assembly. The process characteristics are the locations of each subassembly relative to each other.

There are eight openings for a BIW of a four-door sedan. They are: (1) Motor compartment; (2) windshield; (3) left-side front door; (4) right-side front door; (5) left-side rear door; (6) right-side rear door; (7) back light; and (8) deck lid opening (figure 6). As shown in figure 5 , the coordinate system of the measurements is: fore/aft (F/A or X), in/out (I/O or $\mathrm{Y}$ ), and up/down (U/D or $\mathrm{Z}$ ).

Figure 6 shows the critical points measured by the OCMM on a BIW. Each checkpoint could have more than one dimensional measurement depending upon which directional

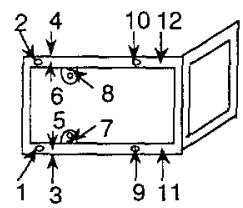

Motor Compartment

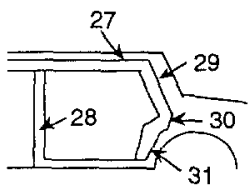

Left Side Rear Door

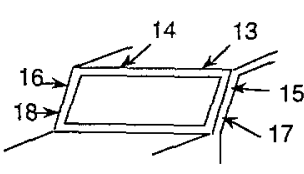

Windshield

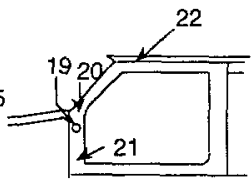

Left Side Front Door

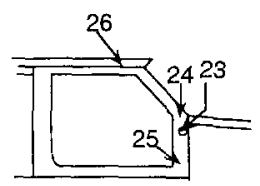

Right Side Front Door

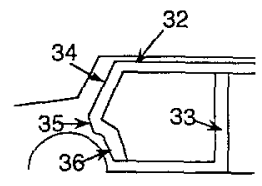

Right Side Rear Door

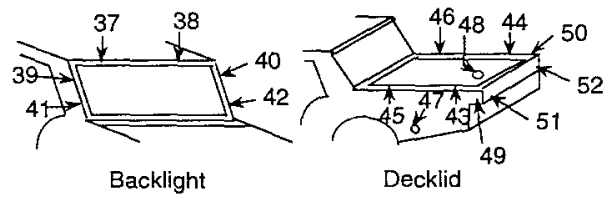

Figure 6. Critical points measured by the OCMM on a BIW. 
measurement of this checkpoint is/are critical to the dimensional quality of the BIW. For example, checkpoint 22 at the left-side front door opening has in/out and up/down measurements, represented by $22-\mathrm{I} / \mathrm{O}$ and 22-U/D because both of the in/out and up/down positions of the roof are important. But checkpoints 20 and 21 at the left front door opening simply have in/out measurement, represented by $20-\mathrm{I} / \mathrm{O}$ and $21-\mathrm{I} / \mathrm{O}$, since only the in/out location of these two points is critical to the dimensional quality of the front door opening. Here $20-\mathrm{I} / \mathrm{O}, 21-\mathrm{I} / \mathrm{O}, 22-\mathrm{I} / \mathrm{O}$, and $22-\mathrm{U} / \mathrm{D}$ are called measurement points.

\subsection{Characteristic matrices}

The location characteristics of a measurement point can be represented using a characteristic vector that links the architecture of the body and the body assembly process. The characteristic vector for a measurement point consists of the direction, the opening, and the subassembly or part that the measurement point is located on. For example, the characteristic vector for measurement point 13-F/A is [fore/aft, windshield, roof]. A characteristic vector can be constructed for every measurement point on the body. For an opening, because a number of points are measured, the characteristic vectors for all these points will constitute a characteristic matrix. For examples, the characteristic matrices for the left-side front door and rear door are shown in tables 1 and 2 . Similar matrices are constructed for the other six openings.

After sudden process changes are detected and classified, measurement points with the same sudden change are grouped based on their characteristic location. Each group will be called a case study. Then, suspect stations can be systematically located according to the categories of each case study. For example, if a direction case study consists of measurement points located at more than one opening or part, only operations at the body framing

Table 1. Characteristic matrix for measurement points at the left-side front door opening.

\begin{tabular}{clll}
\hline Checkpoint & Direction & \multicolumn{1}{c}{ Opening } & \multicolumn{1}{c}{ Part } \\
\hline 19 & fore/aft & LH front door & LH door ring \\
19 & up/down & LH front door & LH door ring \\
20 & in/out & LH front door & LH door ring \\
21 & in/out & LH front door & LH door ring \\
22 & in/out & LH front door & roof \\
22 & up/down & LH front door & roof \\
\hline
\end{tabular}

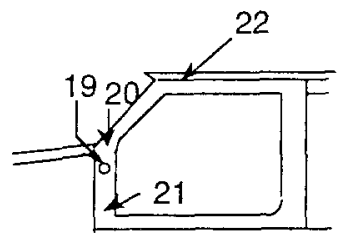

Left Side Front Door 
Table 2. Characteristic matrix for measurement points at the left-side rear door opening.

\begin{tabular}{clll}
\hline Checkpoint & Direction & Opening & Part \\
\hline 27 & in/out & LH rear door & roof \\
27 & up/down & LH rear door & roof \\
28 & in/out & LH rear door & LH door ring \\
29 & fore/aft & LH rear door & LH quarter outer \\
30 & in/out & LH rear door & LH quarter outer \\
31 & in/out & LH rear door & LH quarter outer \\
\hline
\end{tabular}

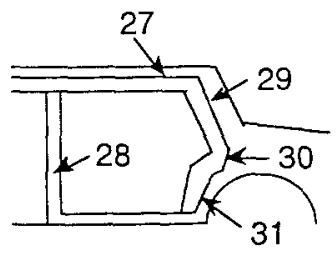

Left Side Rear Door

stage could cause a large variation of this nature. Likewise, the body framing stage would be the suspect if the size of the motor compartment, windshield, back light, or deck lid opening is exhibiting large variation because these openings are determined when the underbody, side frames, roof, shelf, and rear end panel are welded together in this station. The suspect stations are in the stamping or subassembly process for cases involving any one of the door openings because the door ring variation usually results from inconsistencies in the stamping or lay-down side frame subassembly process. Because parts are welded onto other parts in the subassembly process, the suspect stations for part case studies are in the subassembly process. The reason for individual measurement points with large variation could be an OCMM sensor problem or local deformation.

\subsection{Change patterns and root causes of variations}

After the suspect station is located, root causes can be diagnosed based on the type of process changes. Different change patterns in the process correspond to different sources of variations. For example,

1. Sustained means shifts: usually due to tooling failure (e.g., clamp breakage) or material change (e.g., batch to batch)

2. Irregular, sporadic jumps: usually due to interference among parts of interference between tooling and parts

3. Variance changes: usually due to deteriorating tooling condition (e.g., clamp loose).

Therefore, once a change pattern is classified, the sources of variation can be implicated. 


\section{Algorithm for monitoring}

To improve the dimensional quality of a BIW, an algorithm is developed to detect, classify, and group points with process changes by recursive on-line monitoring of the $100 \%$ measurement data from the OCMM.

\subsection{Algorithm development}

This algorithm is designed to monitor the OCMM data of each measurement point on BIWs. This algorithm identifies the dimensional fault using confidence intervals obtained from the sample mean and sample variance of each measurement point before any process change occurs. The sample mean and sample variance could be different from measurement point to measurement point. Therefore, the measurement data from the OCMM for the current BIW have to be normalized before they are sent through this algorithm in order to make this algorithm robust to each measurement point.

This algorithm consists of three parts. The first part uses three different indices simultaneously, a data index, a sample mean index, and a sample variance index, to check whether process changes have occurred. These three indices are represented by a vector as $(a, b, c)$. The second part confirms the occurrence of sudden process changes and classifies them using decision-making rules. The last part groups the measurement points with the same process change into the direction, opening, and subassembly or part group for root cause diagnosis. First, the three monitoring indexes are defined.

The data index is determined by comparing the data with the upper and lower limits of the data range of a $100(1-\alpha) \%$ confidence interval. These upper and lower limits can be found by

$$
\begin{aligned}
& x_{\text {upper limit }}=t_{\alpha / 2, \nu} \\
& x_{\text {lower limit }}=t_{1-\alpha / 2, \nu}
\end{aligned}
$$

where $t_{\alpha / 2, \nu}$ is the critical value of the $t$ distribution with tailed area $\alpha / 2$ and degree of freedom $\nu$. The data index will be

1. 0 if the data is between the upper and the lower limit of the data range

2. 1 if the data is larger than the upper limit of the data range

3. -1 if the data is smaller than the lower limit of the data range.

The sample mean index is assigned based on the comparison between the sample mean and the mean range of a $100(1-\alpha) \%$ confidence interval. The sample mean is the average value of the data for a fixed sample size. The upper and lower limits can be found by

$$
\begin{aligned}
& \mu_{\text {upper limit }}=\bar{x}+t_{\alpha / 2, n-1}\left(\frac{s}{\sqrt{n}}\right) \\
& \mu_{\text {lower limit }}=\bar{x}-t_{\alpha / 2, n-1}\left(\frac{s}{\sqrt{n}}\right),
\end{aligned}
$$


where $\bar{x}$ is the mean value using the sample size of $n ; t_{\alpha / 2, n-1}$ is the critical value of the $t$ distribution with tailed area $\alpha / 2$ and $n-1$ degrees of freedom; and $s$ is the sample standard deviation. The sample mean index is

1. 0 if the sample mean is within the mean range

2. 1 if the sample mean is larger than the upper limit of the mean range

3. -1 if the sample mean is smaller than the lower limit of the mean range.

The sample variance index is determined by examining the sample variance and the upper and lower limits of the variance with a $100(1-\alpha) \%$ confidence interval. The sample variance is the variance of the data for a fixed sample size $n$. The upper and lower limits can be found by

$$
\begin{aligned}
& \sigma_{\text {upper limit }}^{2}=\frac{(n-1) s^{2}}{\chi_{1-\alpha / 2, n-1}^{2}} \\
& \sigma_{\text {lower limit }}^{2}=\frac{(n-1) s^{2}}{\chi_{\alpha / 2, n-1}^{2}}
\end{aligned}
$$

where $n$ is the sample size for calculating the sample variance; $s^{2}$ is the sample variance; and $\chi^{2}$ is the critical value of the $\chi^{2}$ distribution. The sample variance index is determined as

1. 0 if the sample variance is within the variance range, i.e., the sample variance is between the upper and lower limit of the variance range

2. 1 if the sample variance is larger than the upper limit of the variance range

3. -1 if the sample variance is smaller than the lower limit of the variance range.

In order to detect any sudden process change quickly, a moving window is used to calculate the sample mean and sample variance. For example, the sample mean at car number 20 for a specific measurement point is the average value of the measurements from car number 1 to 20 , the sample mean of car number 21 is the average value from car number 2 to 21 , etc.

Table 3 summarizes the upper and lower limits for the data range, mean, and variance. A $95 \%$ confidence interval and a sample size of 20 for calculating the sample mean and variance are used when a set of normalized data with mean 0 and variance 1 is considered.

Table 3. Summary of lower and upper limits of data, sample mean, and sample variance with a $95 \%$ confidence interval and a sample size of 20 for the moving window.

\begin{tabular}{lrcc}
\hline & Data & Sample Mean & Sample Variance \\
\hline Lower limit & -2.09 & -0.47 & 0.58 \\
Upper limit & 2.09 & 0.47 & 2.13 \\
\hline
\end{tabular}


The sample size, which is used to calculate the sample mean and variance, will influence the sensitivity and the detection speed of this algorithm, which will be discussed in sections 3.2 and 3.3, respectively.

A second part of the monitoring algorithm is needed to identify the types of changes once any part of the three-digit index is out of the predetermined range, since the threedigit index only gives an indication that a process change may have occurred. If the threedigit index is $\left(\begin{array}{ll}0 & 0\end{array}\right)$, which indicates no change in the process, then the second part of the monitoring method will not be triggered. On the other hand, if the three-digit index is $\left(\begin{array}{lll}1 & 0 & 0\end{array}\right)$ for some specific measurement point for the current assembled car, it means that this raw data is outside the control limits, but the sample mean and sample variance are still within range. At this moment, instead of concluding that this measurement point has a sporadic jump, the second part of the monitoring will filter ambiguous information from the first part of monitoring. In fact, if the raw data is identified as out of range by the first part of monitoring (three-digit index), it could be the beginning of a mean shift, a sporadic jump, a variance change, or any combination of these. Therefore, the second part of the monitoring is necessary to determine what type of dimensional fault has occurred, using some decision-making rules and more sample statistics. Similarly, if the sample mean or sample variance is out of range, more statistics need to be checked before any conclusions can be drawn.

Figure 7 is the flowchart for the first and second parts of the monitoring, which detect and classify process changes. Note that a sample size of 20 is utilized to estimate the sample mean and variance. For each BIW, the grouping stage (the third part of monitoring) will not be triggered until all measurement points go through the first and second parts of monitoring. The procedures to detect and classify process changes are listed as follows:

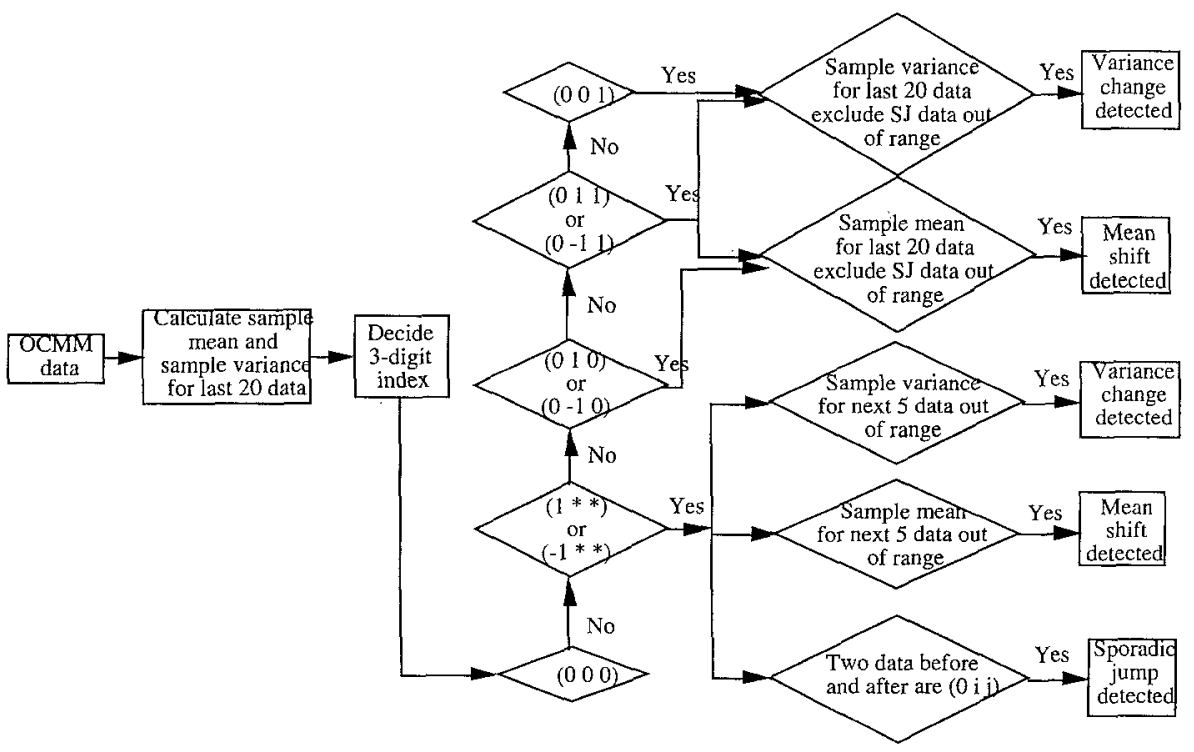

Figure 7. Flowchart for detecting and classifying sudden process changes. 
1. Calculate the sample mean and sample variance once data are available for the current BIW using a sample size of 20 .

2. Form the three-digit index by comparing raw data, sample mean, and sample variance with the upper and lower limits of their corresponding $95 \%$ confidence interval. These upper and lower limits are determined based on the mean and variance of each measurement when no process change has occurred.

3. If the three-digit index is:

a. $\left(\begin{array}{lll}0 & 0 & 0\end{array}\right)$, the process is in control.

b. $\left(\begin{array}{lll}0 & 1 & 1\end{array}\right)$ or $\left(\begin{array}{lll}0 & -1 & 1\end{array}\right)$, then find sample mean and sample variance for the last 20 data, excluding sporadic jump data. A mean shift and/or variance change is identified if the sample mean and/or sample variance are/is outside the limits.

c. $\left(\begin{array}{lll}0 & 0 & 1\end{array}\right)$, then find sample variance for the last 20 data excluding sporadic jump data. A variance change is detected if sample variance is outside the limits.

d. $\left(\begin{array}{lll}0 & 1 & 0\end{array}\right)$ or $(0-10)$, then find sample mean for the last 20 data excluding sporadic jump data. A mean shift is identified if the sample mean is outside the limits.

e. $(1 i j)$ or $(-1 i j)$, where $i$ is $-1,0$, or 1 and $j$ is 0 or 1 , then

I. Find sample mean and sample variance for the next 5 measurements. A mean shift and/or variance change are/is detected if the sample mean and/or sample variance are/is out of range.

II. A sporadic jump is detected if the two three-digit indexes before and after are all $(0 x y)$, where $x$ and $y$ are $-1,0$, or 1 .

The third part of the monitoring algorithm groups the process faults according to the characteristic locations of the measurement points if multiple points experience the same process change for the current BIW. Figure 8 is the flowchart for the grouping stage.

1. After each measurement point is investigated by the first and second parts of monitoring, group the points with process changes into mean shift, sporadic jump, and variance change groups.

2. Group the points with the same process change into the direction, opening, and subassembly or part groups according to their characteristic locations.

Root causes can be investigated after process changes are detected, classified, and grouped. Based on the characteristic location of each group, the suspect station in the assembly process can be located. Once the suspect station is located, the specific fault in this station can be identified on the type of process change.

\subsection{Sensitivity of the algorithm}

The sensitivity of the algorithm for monitoring depends upon two factors. Here, the sensitivity means the minimum magnitude of process change which can be detected. For example, a mean shift greater than $1.5 \mathrm{~mm}$ can be successfully detected, while a mean shift less than $1.5 \mathrm{~mm}$ cannot be detected. Thus, the sensitivity for detecting mean shifts is $1.5 \mathrm{~mm}$. The first factor influencing the sensitivity is the sample size chosen for the moving 


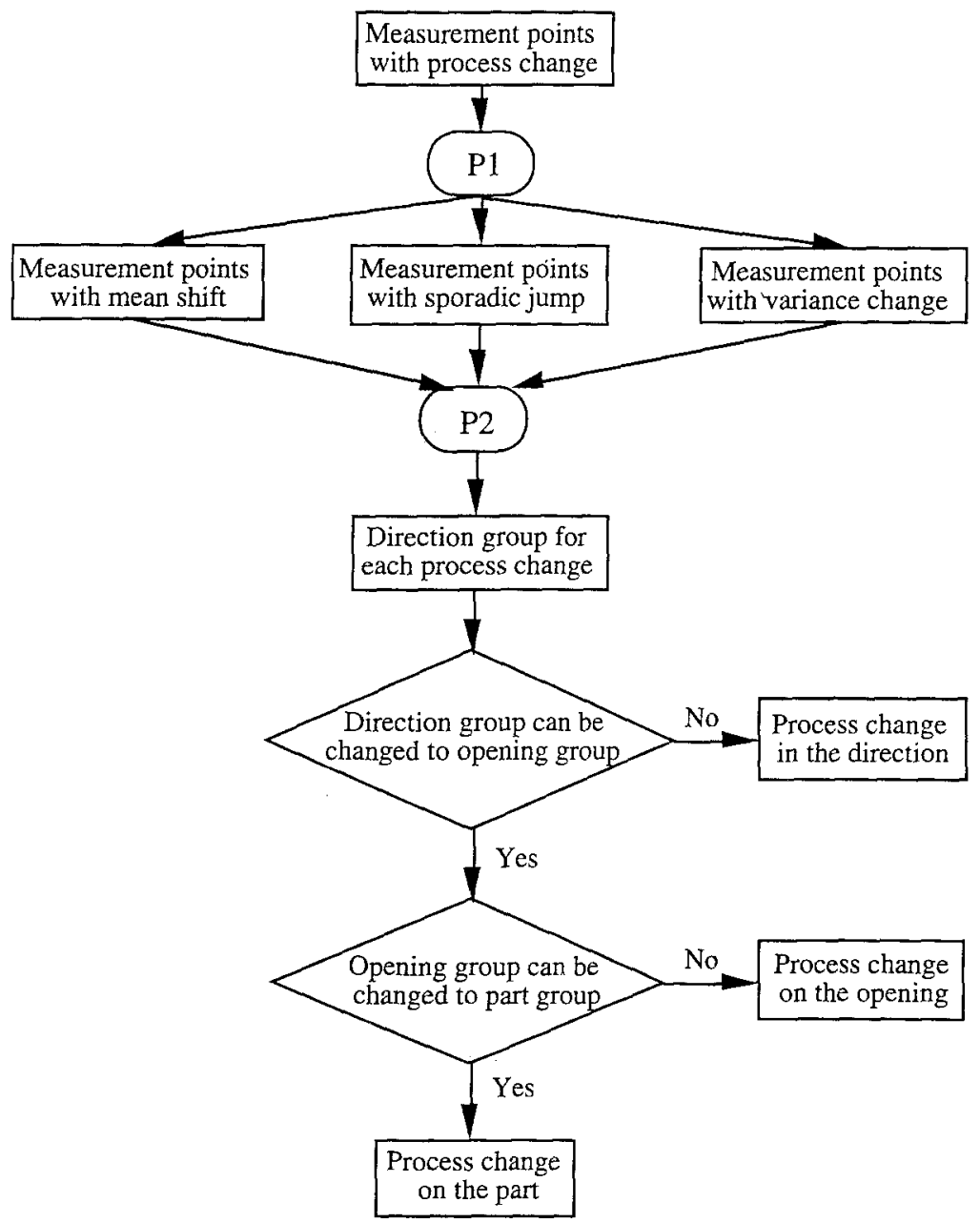

P1: Grouping according to the type of process changes.

P2: Grouping according to the F/A, I/O, and U/D direction.

Figure 8. Flowchart for grouping the points with process changes.

window. The other factor is the sample variance of each measurement point when no change has occurred.

Figures 9,10 , and 11 show the 3-D and contour plots of sensitivity for determining the data, mean, and variance indexes when standard deviation and sample size of window are considered simultaneously. As seen in the figures, the bigger the sample size is, the greater the sensitivity of the algorithm will be. That is, to detect smaller changes, a moving window with larger sample size is needed. In addition, the sensitivity will increase (i.e., a change of smaller magnitude can be detected), when the measurement points have smaller variance before any change occurs. 


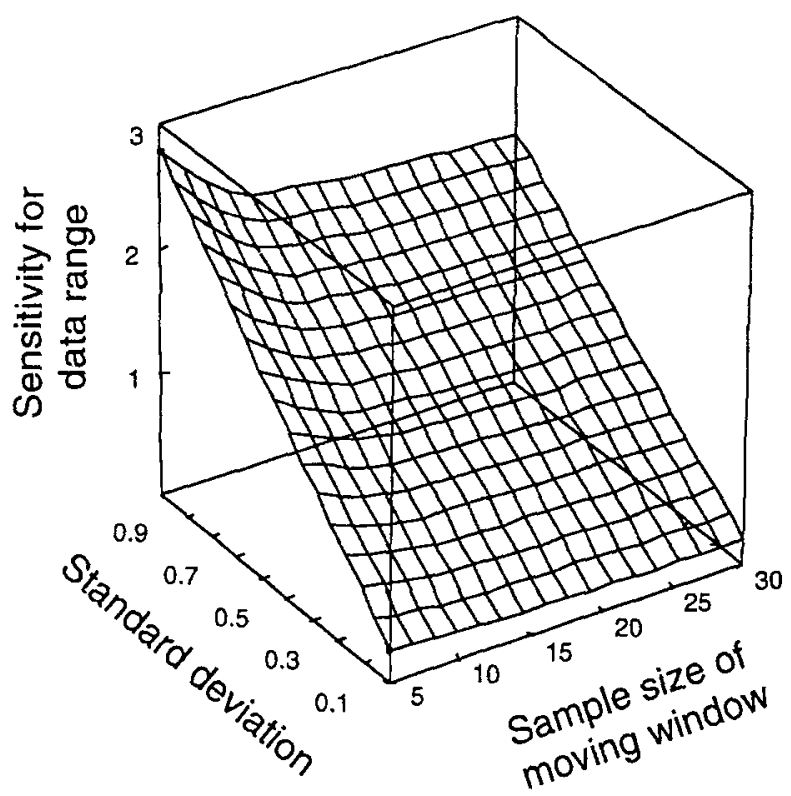

(a)

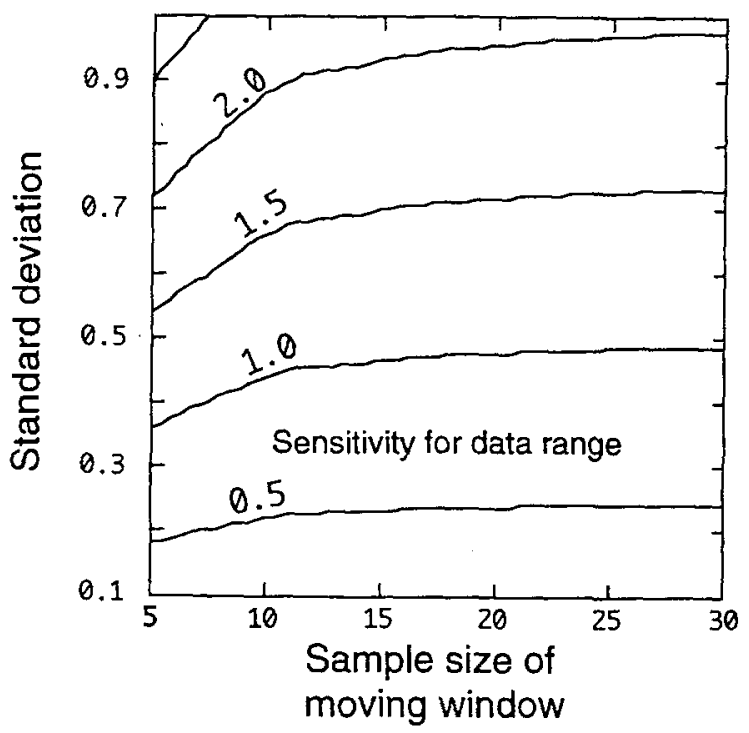

(b)

Figure 9. (a) 3-D plot of sensitivty for data range; and (b) contour plot of sensitivity for data range. 


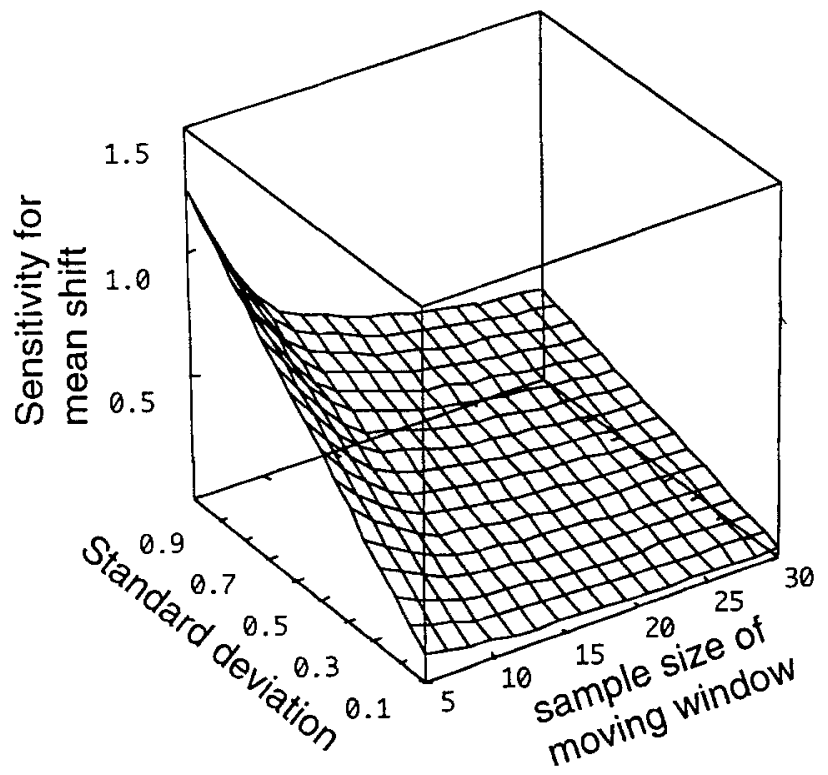

(a)

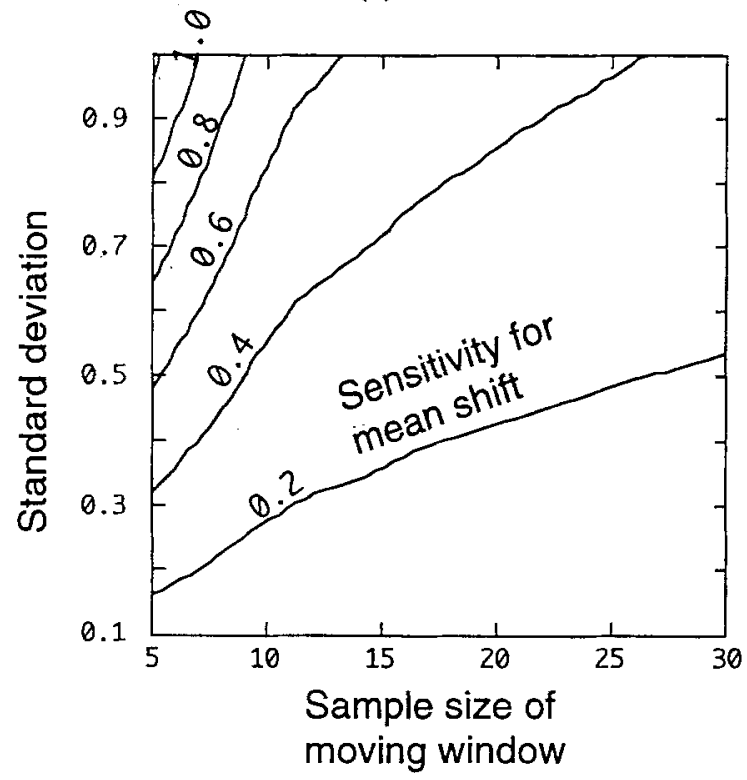

(b)

Figure 10. (a) 3-D plot of sensitivity for mean shift; and (b) contour plot of sensitivity for mean shift. 


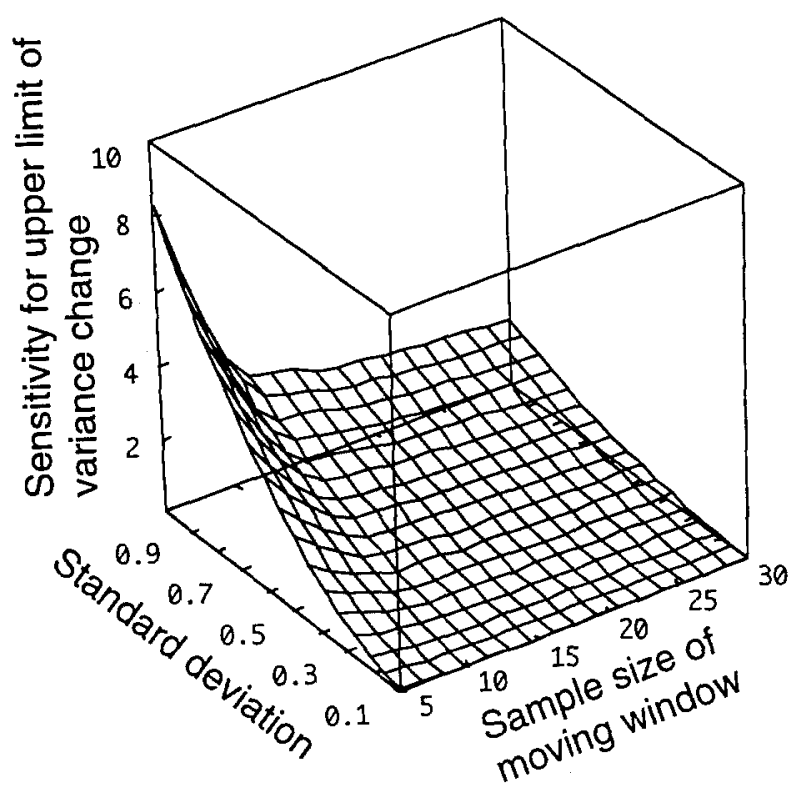

(a)

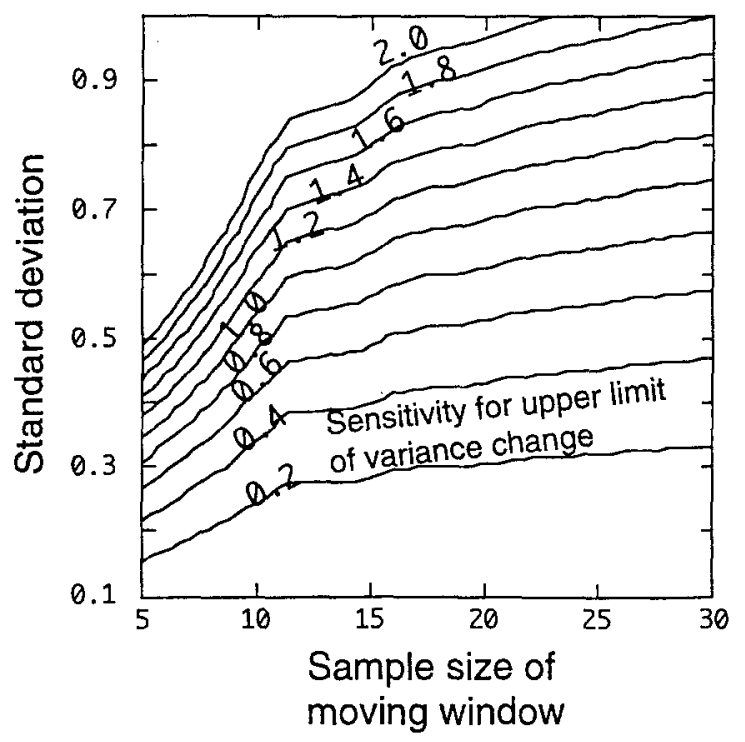

(b)

Figure 11. (a) 3-D plot of sensitivity for upper limit of variance change; and (b) contour plot of sensitivity for upper limit of variance change. 


\subsection{Detection speed}

One of the purposes for developing the monitoring algorithm is to improve the quality and reduce the cost of BIWs in the shortest time. Therefore, quickly detecting process changes is important to this algorithm. In this section, the detection speed for mean shift, sporadic jump, and variance change are investigated using simulation data.

Table 4 summarizes the detection speed for processes with a mean shift. $\Delta \mu$ represents the true amount of mean shift. $S$ is the standard deviation before process change has occurred. The sample size of the moving window is denoted $n$. The results listed in Table 4 are based on the average value of 10 simulations. In general, the higher the value of the mean shift, the faster the process fault can be detected. In addition, no matter what the sample size of the moving window is, a mean shift can always be detected within five car bodies when $\Delta \mu / S$ is greater than 2.0 .

The detection speed for a sporadic jump depends upon how the sporadic jump is defined. In this paper, sporadic jump is defined as follows: The data index is 1 for the current BIW, and the data indexes of two car bodies before and after are 0 . Therefore, the process with a sporadic jump can be detected two car bodies later according to this definition of sporadic jumps.

Table 5 lists the detection speed for detecting a variance change. $S_{1}$ represents the standard deviation after variance change has occurred. The standard deviation before process fault has occurred and the sample size for the moving window are represented by $S$ and $n$, respectively. Similar to table 4 , the values in table 5 are based on the average value of 10 simulations. There is not much difference in the speed of variance change detection, especially when $\left(S_{1} / S\right)^{2}$ is greater than 2.50 .

There is a trade-off between the speed and the accuracy of detecting a mean shift and a variance change if the three-digit index is $(1 i j)$, where $i$ and $j$ are $-1,0$, or 1 . Instead of using the sample size of 20 , a sample size of 5 is used to determine if a dimensional fault occurred after the data index is 1 or -1 . Speed is increased but accuracy is decreased because the upper and lower limits with a $95 \%$ confidence interval are based on a sample size of 20 .

Table 4. Detection speed after mean shift occurred.

\begin{tabular}{cccc}
\hline$\Delta \mu / S$ & $n=10$ & $n=20$ & $n=30$ \\
\hline 0.5 & - & $\geq 18$ & $\geq 23$ \\
1.0 & $\geq 10$ & $\geq 11$ & $\geq 11$ \\
1.5 & $\geq 9$ & $\geq 9$ & $\geq 9$ \\
$\geq 2.0$ & $\geq 5$ & $\geq 5$ & $\geq 5$ \\
\hline
\end{tabular}

Table 5. Detection speed after variance change occurred.

\begin{tabular}{|c|c|c|c|}
\hline$\left(S_{1} / S\right)^{2}$ & $n=10$ & $n=20$ & $n=30$ \\
\hline 2.25 & - & $\geq 7$ & $\geq 9$ \\
\hline 2.50 & - & $\geq 6$ & $\geq 7$ \\
\hline 3.00 & - & $\geq 6$ & $\geq 6$ \\
\hline$\geq 3.00$ & $\geq 6$ & $\geq 6$ & $\geq 6$ \\
\hline
\end{tabular}




\section{Examples}

In this section, examples are given to demonstrate that the monitoring algorithm can detect and classify sudden process changes by recursively monitoring $100 \%$ measurement data obtained from some assembly plants. These examples illustrate the wide variety of process changes which the algorithm must be able to detect in the shortest time.

Figure 12 shows the OCMM data of a measurement point located at the front hinge pillar for 200 cars. After the data are sent through this algorithm, it will give a warning at car number 82 because the data is out of range. Next, the mean shift and variance change are detected at car number 86 by the second part of monitoring because the sample mean and the sample variance of the next five data (including car number 82) are out of range.

An example of detecting a mean shift is illustrated in figure 13. A warning is given at car number 97 since the data is out of range. The process will then be detected and classified as a mean shift at car number 101 .

With reference to figure 14, eight cars with sporadic jump at F-I/O are detected two jobs after the sporadic jump has occurred by this detection algorithm. In addition, a mean shift that occurred at car number 136 was detected at car number 140.

Figure 15 shows that a mean shift occurred at four points on the roof. Note that the positive directions in the in/out direction at the left and right sides are opposite. Thus,
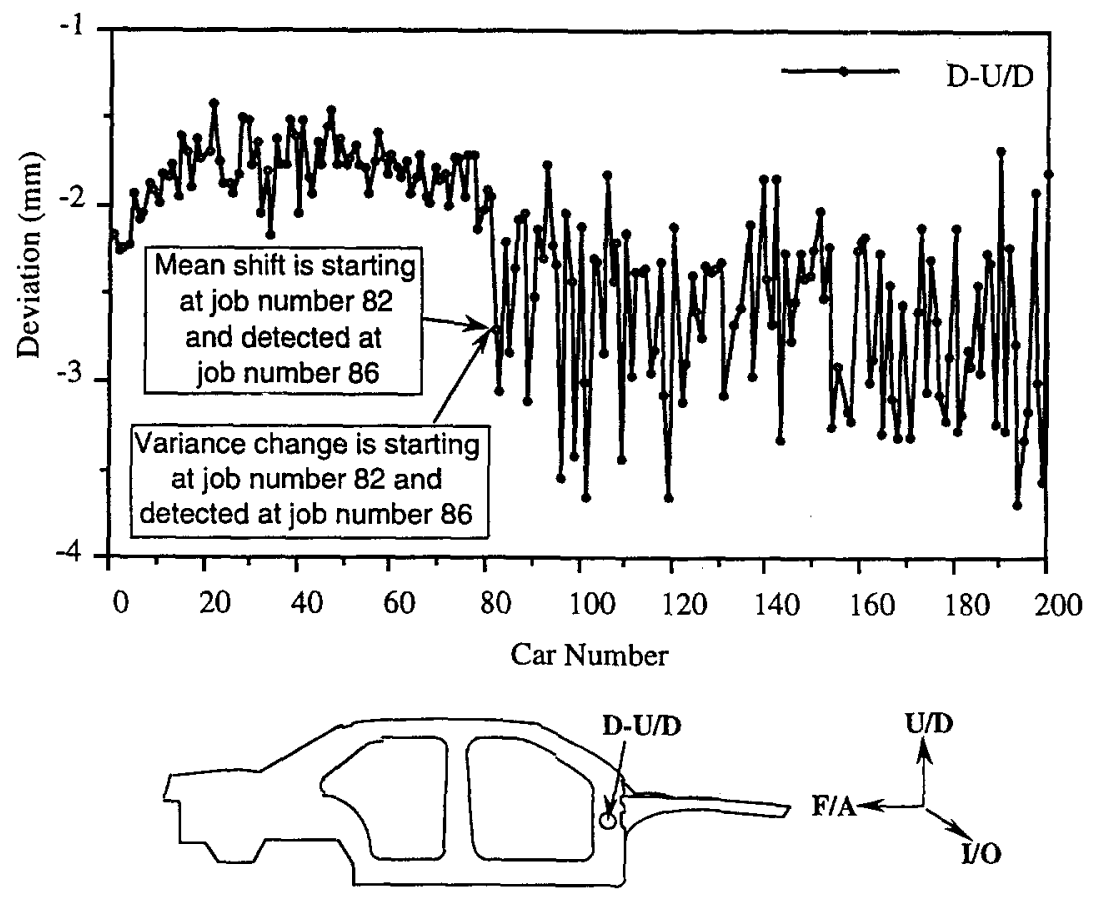

Figure 12. A process with simultaneous mean shift and variance change at car number 82, identified at car number 86. 

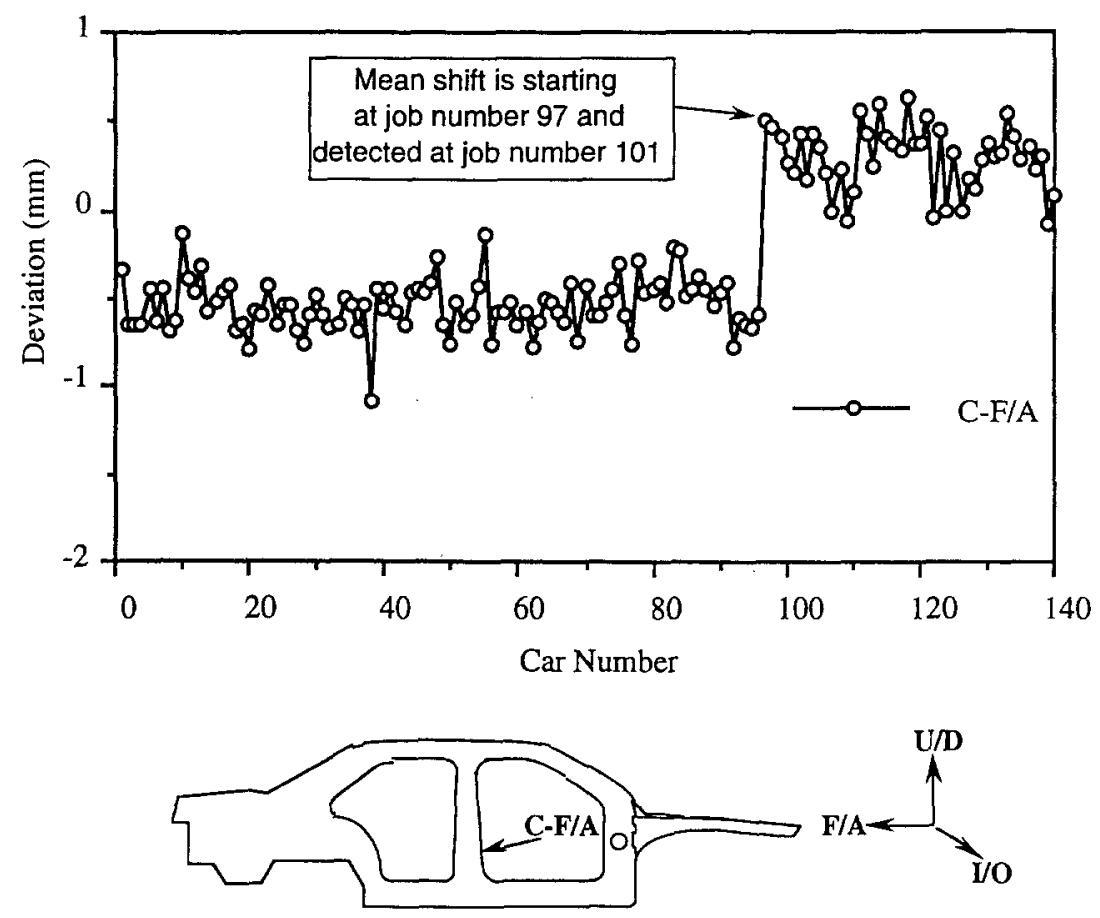

Figure 13. A process with a mean shift at car number 97, detected at car number 102 .

points $22-\mathrm{I} / \mathrm{O}$ and $27-\mathrm{I} / \mathrm{O}$ moved to the right while points $26-\mathrm{I} / \mathrm{O}$ and $32-\mathrm{I} / \mathrm{O}$ also move to the right. By using the monitoring algorithm, a mean shift occurring at these four points on the same BIW is detected. Then, the third part of monitoring is used to group these four points for root cause diagnosis. A mean shift group is found because these four points have the same process change, a mean shift. The next step is to check whether the points in the mean shift group are in the same direction, opening, or subassembly or part. According to their characteristic location, they are located in the $\mathrm{V} / \mathrm{O}$ direction and on the roof. It was concluded that the four measurement points on the roof shift to the right at the same time. This mean shift is the result of the movement of the NC blocks at the robogate. The NC blocks determine the in/our position of the roof when the underbody, side frames, roof, shelf, and rear end panel are welded together. Figure 16 shows the computer output of the monitoring algorithm. The number in parentheses is the three-digit index by which the second stage of monitoring is triggered. In addition to the mean shift, a number of sporadic jumps are detected and grouped.

\section{Conclusions}

1. An algorithm was developed to detect the occurrence of any sudden process change by recursively monitoring the $100 \%$ measurement data from the OCMM. This algorithm can (a) Detect which BIW and which measurement points have a process change; (b) classify 

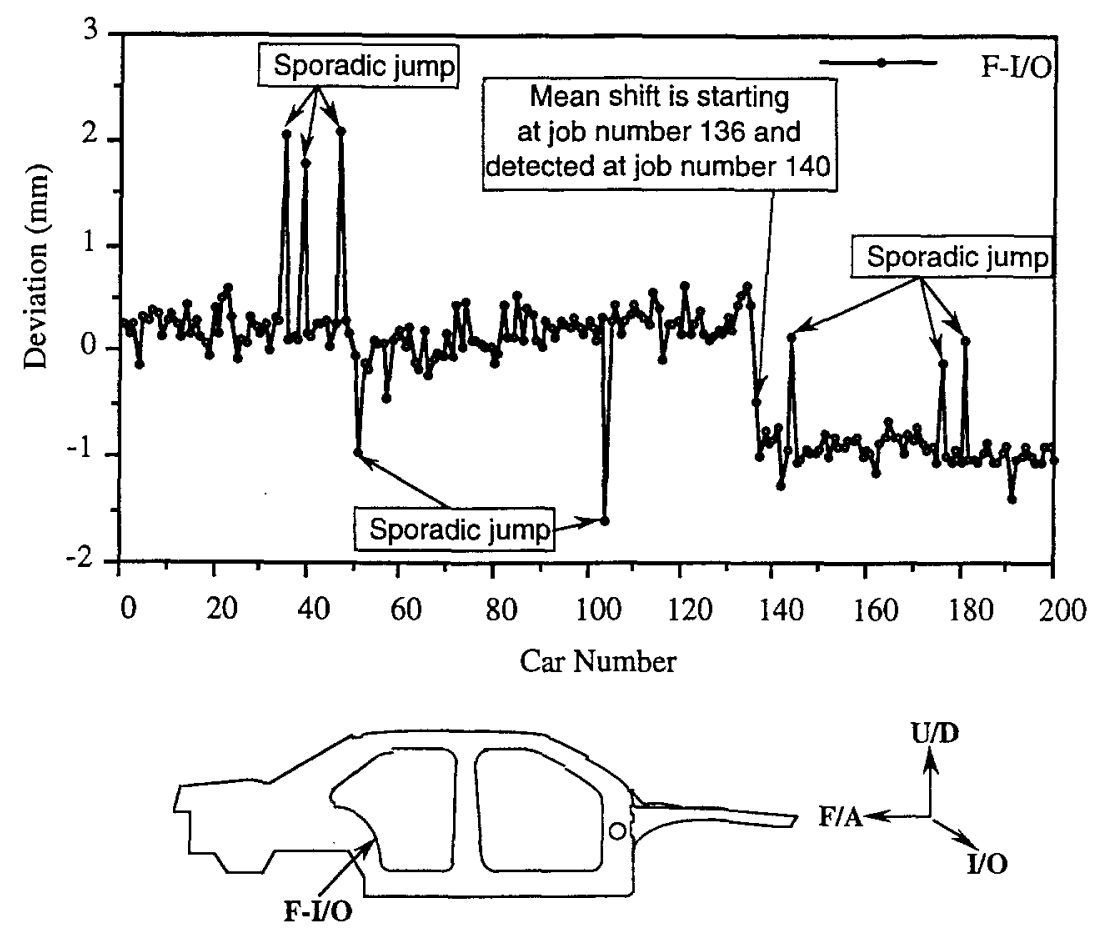

Figure 14. A process with eight sporadic jumps identified two jobs later. In addition, a mean shift is identified at car number 141 which occurred at car number 136 .

the process changes as a mean shift, sporadic jump, variance change, or any combination of these three; and (c) group the points with the same process change according to their characteristics location for root cause diagnosis.

2. The sensitivity of the detection algorithm depends on two factors. One factor is the sample size of the moving window; the other is the sample mean and variance of each measurement point before any process change has occurred.

3. The detection speed of the algorithm is found using simulation data for different types and different amounts of process changes, and different sample sizes of the moving window when the sample mean and sample variance are calculated. In general, the higher the value of the mean shift, the faster it can be detected. A process with a sporadic jump can be detected two cars later based on the definition of sporadic jump. There is not much difference in the speed of detecting variance change, especially when the ratio of the variances after and before a process change occurs is greater than 2.50.

4. The monitoring algorithm has been implemented and tested. Three sets of OCMM data obtained from assembly plants demonstrate that this detection algorithm can identify and classify sudden process changes. Another set of data illustrates the detection, classification, and grouping of points having the same process change. 


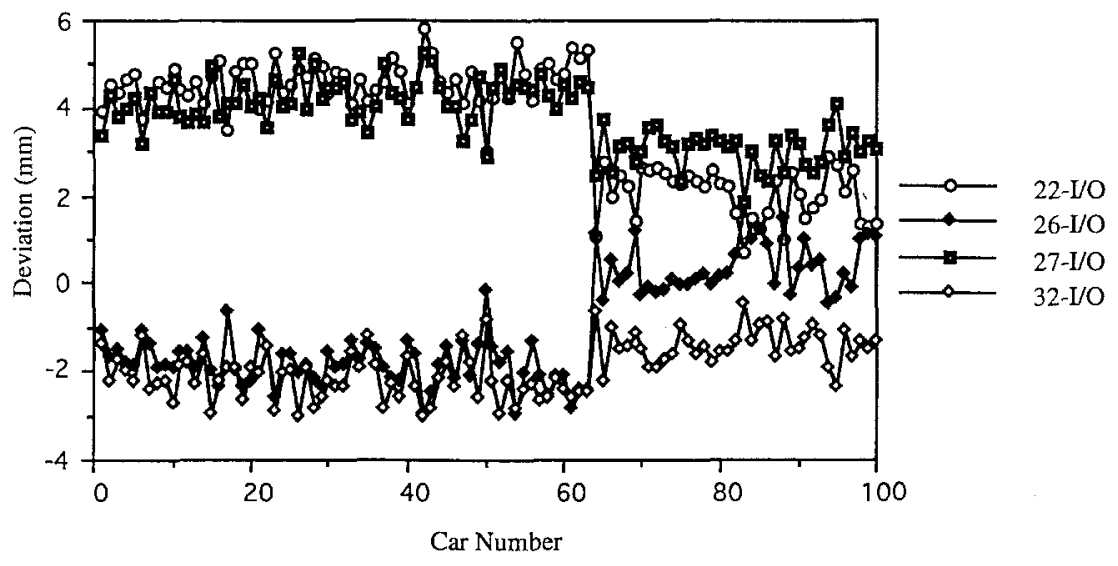

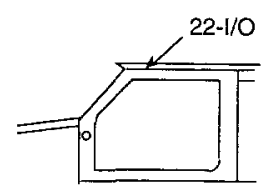

Left Side Front Door

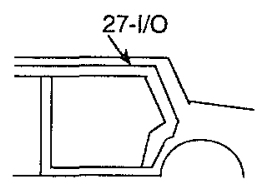

Left Side Rear Door

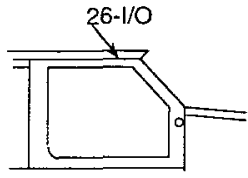

Right Side Front Door

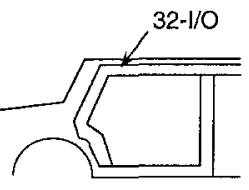

Right Side Rear Door

Figure 15. Four points located on the roof have simultaneous mean shifts. 

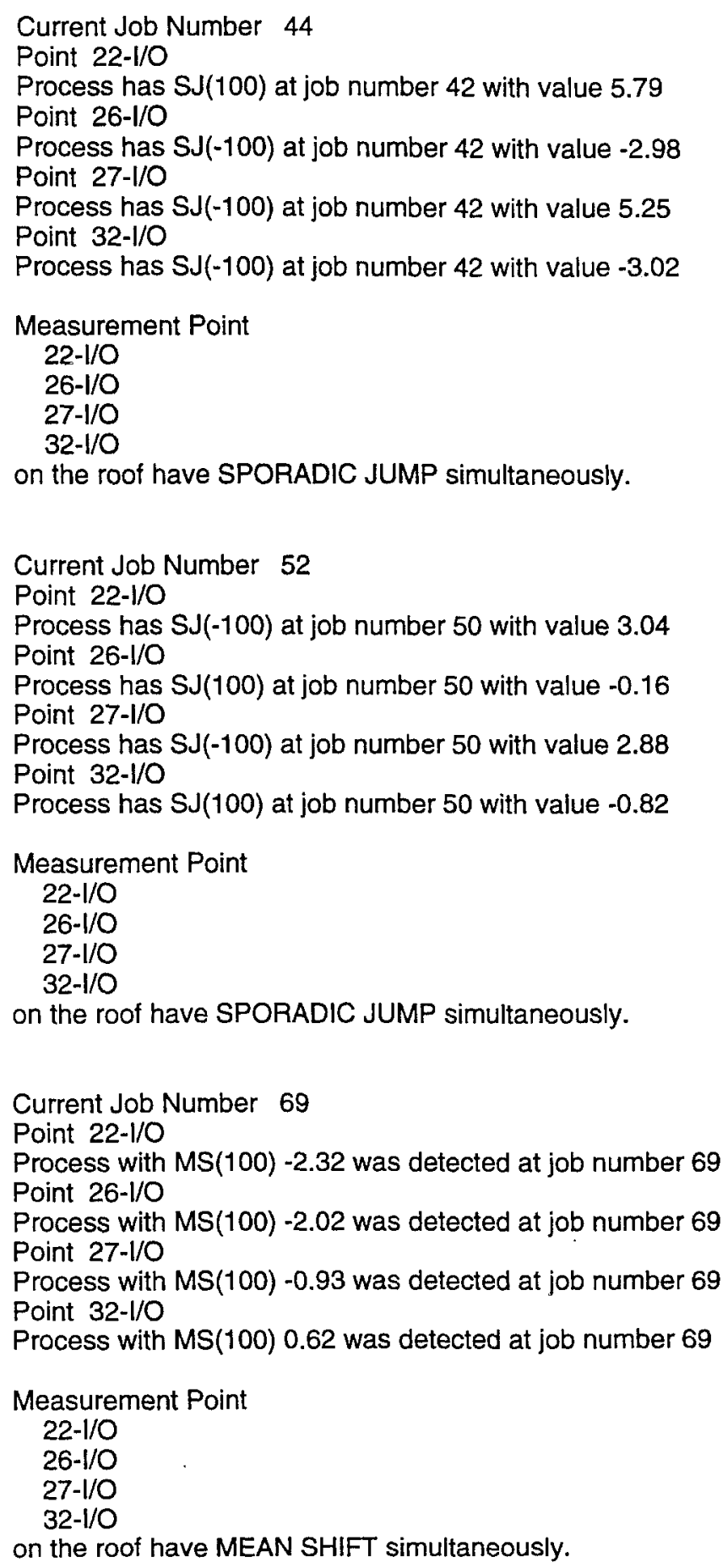

Figure 16. Computer output for the data shown in figure 15. 


\section{References}

Box, G. and Kramer, T., "Statistical Process Monitoring and Feedback Adjustment-A Discussion," Technometrics, Vol. 34, No. 3, pp. 251-267 (August 1992).

Contreras, L.E., "Implementations Strategies for On-Line Statistical Process Control Systems," in Statistical Process Control in Automated Manufacturing, Keats, J.B. and Hubele, N.F. (Eds.), Marcel Dekker Inc., New York, N.Y. pp. 33-42 (1989).

Dooley, K.J. and Kapoor, S.G., "An Enhanced Quality Evaluation System for Continuous Manufacturing Processes, Part 1: Theory," Transactions of the ASME, Journal of Engineering for Industry, Vol. 112, No. 1, pp. 57-62 (February 1990a).

Dooley, K.J. and Kapoor, S.G., "An Enhanced Quality Evaluation System for Continuous Manufacturing Processes, Part 2: Application," Transactions of the ASME, Journal of Engineering for Industry, Vol. 112, No. 1, pp. 62-68 (February 1990b).

Guo, Y. and Dooley, K.J., "Identification of Change Structure in Statistical Process Control," International Joumal of Production Research, Vol. 30, No. 7, pp. 1655-1669 (July 1992).

Hawkins, D.M., "The Detection of Errors in Multivariate Data Using Principal Components," Journal of the American Statistical Association, Vol. 69, No. 346, pp. 340-344 (June 1974).

Keats, J.B., "Process Control in Automated Manufacturing: Some Key Issues" Statistical Process Control in Automated Manufacturing, Keats, J.B. and Hubele, N.F. (Eds.), Marcel Dekker Inc., New York, N.Y., pp. 17-31 (1989).

Shewhart, W.A., Economic Control of Quality of Manufactured Product, Van Nostrand, New York, NY (1931). Taguchi, G., Introduction to Quality Engineering, Asian Productivity Organization, Tokyo, Japan (1986).

Wu, S.M. and Hu, S.J., "Impact of $100 \%$ In-Process Measurement on Statistical Process Control in Automobile Body Assembly," Monitoring and Control in Manufacturing, S. Liang and T.C. Tsao (Eds.), ASME Winter Annual Meeting, Dallas, Texas, pp. 433-448 (November 1990).

Wu, S.M., Ni, J., and Hu, S., "Next Generation Quality Control in Manufacturing-Real-Time Defect Prevention," Proceedings of the ASME Winter Annual Meetings, San Francisco, CA., pp. 1-11 (November 1989). 